\title{
Development and Dissemination of a Strengths-Based Indigenous Children's Storybook: "Our Smallest Warriors, Our Strongest Medicine: Overcoming COVID-19"
}

\author{
Victoria M. O’Keefe*, Tara L. Maudrie, Allison Ingalls, Crystal Kee, Kristin L. Masten, \\ Allison Barlow and Emily E. Haroz
}

Center for American Indian Health, Department of International Health, Johns Hopkins Bloomberg School of Public Health, Baltimore, MD, United States

OPEN ACCESS

Edited by:

Rene Begay,

University of Colorado Anschutz Medical Campus, United States

Reviewed by:

Mark Brough,

Queensland University of

Technology, Australia

Tanya Kaefer,

Lakehead University, Canada

${ }^{*}$ Correspondence: Victoria M. O'Keefe vokeefe3@jhu.edu

Specialty section:

This article was submitted to

Race and Ethnicity,

a section of the journal

Frontiers in Sociology

Received: 28 September 2020 Accepted: 01 March 2021

Published: 23 March 2021

Citation:

O'Keefe VM, Maudrie TL, Ingalls $A$,

Kee C, Masten KL, Barlow A and

Haroz EE (2021) Development and Dissemination of a Strengths-Based Indigenous Children's Storybook: "Our

Smallest Warriors, Our Strongest Medicine: Overcoming COVID-19".

Front. Sociol. 6:611356.

doi: 10.3389/fsoc.2021.611356
The traditions, strengths, and resilience of communities have carried Indigenous peoples for generations. However, collective traumatic memories of past infectious diseases and the current impact of the coronavirus disease 2019 (COVID-19) pandemic in many Indigenous communities point to the need for Indigenous strengths-based public health resources. Further, recent data suggest that COVID-19 is escalating mental health and psychosocial health inequities for Indigenous communities. To align with the intergenerational strengths of Indigenous communities in the face of the pandemic, we developed a strengths- and culturally-based public health education and mental health coping resource for Indigenous children and families. Using a community-engaged process, the Johns Hopkins Center for American Indian Health collaborated with 14 Indigenous and allied child development, mental health, health communications experts and public health professionals, as well as a Native American youth artist. Indigenous collaborators and Indigenous Johns Hopkins project team members collectively represented 12 tribes, and reservation-based, off-reservation, and urban geographies. This group shared responsibility for culturally adapting the children's book "My Hero is You: How Kids Can Fight COVID-19!" developed by the Inter-Agency Standing Committee Reference Group on Mental Health and Psychosocial Support in Emergency Settings and developing ancillary materials. Through an iterative process, we produced the storybook titled "Our Smallest Warriors, Our Strongest Medicine: Overcoming COVID-19" with content and illustrations representing Indigenous values, experiences with COVID-19, and strengths to persevere. In addition, parent resource materials, children's activities, and corresponding coloring pages were created. The book has been disseminated online for free, and 42,364 printed copies were distributed to early childhood home visiting and tribal head start programs, Indian Health Service units, tribal health departments, intertribal, and urban Indigenous health organizations, Johns Hopkins Center for American Indian Health project sites in partnering communities, 
schools, and libraries. The demand for and response to "Our Smallest Warriors, Our Strongest Medicine: Overcoming COVID-19" demonstrates the desire for Indigenous storytelling and the elevation of cultural strengths to maintain physical, mental, emotional, and spiritual health during the COVID-19 pandemic.

Keywords: Indigenous, American Indian/Alaska Native, COVID-19, coronavirus, mental health, youth, childhood

\section{INTRODUCTION}

Indigenous (American Indian/Alaska Native/First Nations/Métis/Inuit) ${ }^{1}$ peoples and nations are strong. Each tribe, village, and community carries knowledges, teachings, and practices passed down from their ancestors to current citizens that will continue to future generations. Though there are differences across tribes and communities, Indigenous knowledge "has sustained their communities and includes a deep belief in the connectedness of all creation across time and space, with relationships between past, present, and future entities. These relational connections correspond with responsibilities to place; all beings (self, family, people, clan, animals); the physical world (land, water, plants); ancestors (past and future); and the spirit world" (p. 4; Walters et al., 2020). In addition to providing meaning and a foundation for individual and community action, Indigenous knowledges and practices provide instructions for health and wellness (Walters et al., 2020). These intergenerational strengths have persisted against land theft, attempted genocide and ethnocide-including federal policies enforcing cultural oppression-and ongoing interpersonal and institutional racism.

Infectious diseases have been a threat to Indigenous populations since the arrival of Europeans. Historical records show that waves of diseases like smallpox, cholera, scarlet fever, influenza, and tuberculosis took more Indigenous lives than wars, enslavement, and starvation combined (Nabokov, 1999). Further, stories of intentional spread of diseases as a form of biological warfare against Indigenous peoples (e.g., smallpox blankets) are well-documented (Nabokov, 1999; Smith, 2013). Ancestral traumatic memories of these devastating events remain within Indigenous communities (Brave Heart and Debruyn, 1998).

Today, a legacy of broken treaties and institutional injustices has led to persistent underfunding of federal programs that contribute to social and health inequities within many American Indian/Alaska Native communities (U.S. Commission on Civil Rights, 2018). For example, the Indian Health Service, the primary agency responsible for American Indian/Alaska Native healthcare in the U.S., was funded in Fiscal Year 2020 at $\$ 6.4$ billion (Indian Health Service, 2020a), $\sim \$ 41.6$ billion dollars less than what is needed to adequately serve American Indians/Alaska Natives (National Tribal Health Budget Formulation Workgroup, 2020). The resulting social determinants that underlie health inequities among American Indian/Alaska Native communities, include, but are not limited

\footnotetext{
${ }^{1} \mathrm{We}$ acknowledge all Indigenous peoples and nations are strong across the world. In this manuscript we focus on North American Indigenous populations, who were the target audience of the current storybook.
}

to, poverty, food and water insecurity, and inadequate access to hospitals, schools, housing, roads and public transit, internet, and cellular phone service (U.S. Commission on Civil Rights, 2018). These factors and existing inequities have increased coronavirus disease 2019 (COVID-19) risk transmission and its impact, resulting in American Indians/Alaska Natives experiencing COVID-19 incidence that is 3.5 times higher than the incidence among White individuals, and the highest COVID19 hospitalization rates of all racial groups in the U.S. (Hatcher et al., 2020; Rodriguez-Lonebear et al., 2020; Centers for Disease Control and Prevention, n.d.). A study conducted in April 2020 examining associations between household and community characteristics and COVID-19 infection rates in 278 American Indian reservation communities in the U.S. found strong correlations between COVID-19 incidence and lack of indoor plumbing and non-English speaking households (RodriguezLonebear et al., 2020). Further, overcrowded homes limit the ability to abide by physical distancing and quarantining COVID19 guidelines, while inadequate access and infrastructure of internet and cellular phone service prevent access to telehealth and educational resources (U.S. Commission on Civil Rights-Written testimony of President Fawn Sharp, National Congress of American Indians, 2020). Together, these data demonstrate profound injustices that are exacerbating the COVID-19 pandemic for many American Indian/Alaska Native communities (Rodriguez-Lonebear et al., 2020; U.S. Commission on Civil Rights-Written testimony of President Fawn Sharp, National Congress of American Indians, 2020).

Moreover, the mental and spiritual health impacts of COVID19 related losses are particularly profound given traditional values emphasizing the importance of family, community connectedness, and intergenerational learning (Cajete, 2000; Ullrich, 2019). These impacts may include loss of tribal Elders who are carriers of Indigenous knowledges and languages, the inability to engage in ceremonies and community gatherings, reliving memories of past traumas, and isolation from extended family (Indian Health Service, 2020b; National Indian Health Board, 2020; Urban Indian Health Board, 2020). A survey of 1,400 Indigenous peoples (First Nations/Métis/Inuit) in Canada ages 15 and older showed that $60 \%$ reported their mental health had worsened since physical distancing was implemented as a COVID-19 prevention strategy (Arriagada et al., 2020). In the same survey, nearly half of Indigenous women and approximately one-third of Indigenous men described most of their day as "quite a bit" to "extremely stressful" (Arriagada et al., 2020). Though we currently do not have equivalent data in the U.S., these data likely represent similar mental health impacts experienced by American Indians/Alaska Natives 
given that traditional lands cross country borders for some tribes, as well as similar experiences of collective trauma and contemporary health inequities in both countries (King et al., 2009). Helping Indigenous children and families cope with such hardship is critical to comprehensive COVID-19 response and recovery efforts.

Indigenous peoples and nations are demonstrating their commitment to protecting their communities during the COVID-19 pandemic. For example, tribal nations in the U.S. are showing "sovereignty in action" through mandated stay-athome orders, in-person contact tracing and supportive isolation, and developing incident command systems - all exemplars that can be replicated at local, state, and national levels in non-Native communities to slow the COVID-19 spread (Native Governance Center, n.d.). To align with the strengths and collective action of Indigenous communities, the public health response must also include strengths-based approaches aligning with Indigenous knowledges and practices to provide practical, accessible, and culturally-driven resources for families and communities. This reinforces reshaping the COVID-19 narrative from one of fear, despair, and helplessness, to one of empowerment and hope that draws upon the inherent intergenerational values and strengths in Indigenous children, families, and communities to overcome this current challenge. Further, developing persuasive and inspirational messaging related to COVID-19 that reflects Indigenous values can form the basis of a social justice solution grounded in Indigenous health promotion and survivance (Vizenor, 2008).

The purpose of this paper is to describe the development and dissemination of "Our Smallest Warriors, Our Strongest Medicine: Overcoming COVID-19" (OSWOSM), a storybook written for the Kindergarten to 5th grade age group and their families, to provide strengths- and culturally-based public health education and mental health coping resources in response to the COVID-19 pandemic. OSWOSM is an adaptation of "My Hero is You: How Kids Can Fight COVID-19!", a book developed by the Inter-Agency Standing Committee Reference Group on Mental Health and Psychosocial Support in Emergency Settings (Kovach, 2010; Inter-Agency Standing Committee, 2020). The choice to adapt this book as a story told for and by Indigenous caregivers and their children is guided by recognition of the importance of Indigenous storytelling as a tradition that has supported the well-being and resilience of Indigenous communities since time immemorial (Kovach, 2010). While there are specific and important tribal and community differences in knowledges, values, and cultural teachings, we aimed to tap into the shared practice of storytelling with characters representing broad traditions and Indigenous geographies to reach and relate to as many Indigenous children and families as possible.

\section{MATERIALS AND METHODS}

\section{Adaptation Process}

The Johns Hopkins Center for American Indian Health (CAIH) formed a collaborative team of 14 child development, mental health, and health communications experts, public health professionals, and a Native American youth artist. The collaborator workgroup represented 12 tribes, both on- and offreservation, and urban Indigenous geographies, as well as nonIndigenous allies, whose purpose was to culturally adapt content and illustrations to represent Indigenous peoples, values, and communal experiences with COVID-19. Of note, the majority of the collaborator workgroup were parents and/or grandparents with children and grandchildren within the targeted age range of the storybook. This allowed collaborators to provide input based on both their professional expertise as well as their personal experiences about how children and families are impacted during the COVID-19 pandemic. In addition, some workgroup members read early drafts to their own children in the targeted age range of the book and the feedback from children was incorporated into subsequent drafts.

The workgroup met a total of three times virtually via video conference. The first meeting aimed to reach consensus for story themes, character development, and to discuss other major adaptations from the original "My Hero is You: How Kids Can Fight COVID-19!" book. After the initial meeting, one of the workgroup members (Crystal Kee, Diné; fourth author) developed a storyboard for OSWOSM. During the storyboard development, Kee also consulted with two knowledge keepers (including one Elder) from her tribe and integrated their input into the storyboard. This storyboard was presented to the full workgroup for feedback during the second video conference meeting. Following this meeting, the CAIH team integrated feedback from the workgroup as they drafted the first version of OSWOSM. Written feedback and direct edits to the book content were obtained via email from workgroup members. The Native American youth artist also presented sketches during the second and third video conference meetings to receive feedback from the workgroup about how the characters and scenes reflected content and themes. Final illustrations were presented via email to the workgroup for final feedback before being added with the content into OSWOSM.

In addition, the workgroup identified the importance of developing parent resources and children's activities to accompany the book. A subgroup with multi-disciplined Indigenous mental health and child development expertise volunteered to draft and revise the parent resources and the Native American youth artist developed illustrations. Each individual in the subgroup volunteered for a particular resource to draft content, emailed the draft to all other subgroup members for feedback, and the CAIH team provided final edits. Nine total resources were developed. The Native American youth artist developed six coloring pages from illustrations found throughout the OSWOSM storybook. Finally, the CAIH team used these coloring pages to develop six Indigenous language activity pages to encourage children and families to learn and practice speaking their tribal languages.

\section{Dissemination of the Book}

We used several dissemination strategies to encourage the broadest reach and impact of the book and ancillary materials across Indigenous communities. First, we created a webpage where the book and materials could be downloaded for free (https://bit.ly/NativeStrongMedicine). We developed a social 
media campaign to promote the storybook and parent/child resources through the CAIH Facebook, Instagram, and Twitter accounts, as well as the CAIH newsletter, which currently has 6,781 subscribers. In addition, we shared the webpage and social media posts with eight national U.S.-based Indigenous advocacy and grassroots organizations to promote the book among additional online audiences.

To mitigate the lack of broadband access within some Indigenous communities (U.S. Commission on Civil Rights, 2018; National Congress of American Indians, n.d.), which may prohibit some communities from accessing the book and resources online, we also disseminated print books to Indigenous communities through several methods. First, we used CAIH's nationally recognized home-visiting program, Family Spirit ${ }^{\circledR}$. Family Spirit is an evidence-based, culturally tailored homevisiting program that promotes optimal health and well-being for parents and their children (Barlow et al., 2006, 2013, 2015; Walkup et al., 2009). It combines the use of paraprofessionals from the community as home visitors and a culturally focused, strengths-based curriculum as a core strategy to support young families from pregnancy until their child's 3rd birthday. Parents gain knowledge and skills to promote healthy development and positive lifestyles for themselves and their children. Family Spirit has been scaled nationally to programs called "Family Spirit Affiliates" in over 130 tribal communities and 4 non-Native sites across 21 states. All Family Spirit Affiliates were contacted via email with a survey asking how many active families they serve. All sites that completed the survey were sent one book per family served to distribute.

Second, the CAIH has a long-standing memorandum of understanding with the Indian Health Service (IHS). We leveraged this existing partnership to disseminate the storybook to families through IHS service units. Third, CAIH distributed wellness boxes to individuals and families in several tribal partner communities (e.g., White Mountain Apache Tribe, Navajo Nation, and 11 Ojibwe Bands) where the CAIH has offices operated by local Indigenous employees. "Our Smallest Warriors, Our Strongest Medicine: Overcoming COVID-19” was included in these wellness boxes for families with children in the target age range. Finally, we advertised that IHS or tribal/village health departments, community-based organizations that serve Indigenous families, and intertribal or urban Indigenous health programs could order bulk print copies for Indigenous families they serve. These orders were coordinated on a first come, first served basis through the CAIH website and direct emails with the storybook team.

\section{Dissemination Evaluation}

As part of our dissemination efforts, we piloted an evaluation strategy to understand the reach and impact of OSWOSM. This included indicators of reach by tracking the number of books printed, number of books sent to regional sites for distribution, number of families or individuals that received the books (tracked through REDCap (Harris et al., 2009), an electronic data capture tool hosted at Johns Hopkins University sent to those distributing the book), number of webpage visits, and the volume of social media impressions and engagements. We also attempted to measure the social and emotional impact the book had on children through an anonymous caregiver survey using Qualtrics (Qualtrics, Provo, UT; Qualtrics, 2020) distributed through a QR code in the book and on the webpage. The survey questions were developed to measure overall satisfaction with the book, COVID-19 knowledge, and caregiver assessment of children's self-efficacy to implement protective behaviors and strategies against COVID-19.

\section{RESULTS}

\section{Adaptation}

The cultural adaptation process and finalizing book content and illustrations took 5 weeks. The rapid production time was intentional in order to address the COVID-19 crisis as quickly as possible with this resource. The final content of the book features youth twins, named Tara and Virgil, as narrators who live with their mother (a nurse), their father (a tribal leader), and their grandmother (Figure 1). During the adaptation process, the workgroup shared that some tribes have traditional stories about twins. Featuring fraternal twins was also done in an effort to allow a wide range of children to identify with the kids in the story. Finally, the Native American artist and workgroup collaborated during meetings to decide how each character is depicted. For example, the group felt that the twins should both feature long hair and not be clearly dressed in stereotypical gendered clothing. Further, the workgroup aimed to capture three important roles that community members are serving in to assist with the COVID-19 response: nurses, tribal leaders, and children's intergenerational caregivers (grandmother). The workgroup decided to portray the twins' mom as a nurse, a frontline COVID-19 worker, and their dad as a tribal leader, who might be guiding policies for community well-being during the pandemic. The twins' grandmother represents an important cultural keeper as an Elder who teaches the twins about traditions, such as learning the importance of earning eagle feathers through acts of service and demonstrating respect and responsibility.

Within the story, the twins have a dream in which they visit four friends in each of the four directions with their grandfather, who has passed on to the spirit world. Their grandfather takes the form of an eagle, an important cultural symbol (e.g., spiritual messenger) for many Indigenous peoples. The friends each share their unique family and community experiences with COVID-19. For example, one friend shares that someone in the household got COVID-19 and how his family kept themselves and others safe when this happened. This friend also shared that a relative built a handwashing station for the family, to depict Indigenous families who experience water insecurity and how communities are working on solutions to these issues during the pandemic. Other friends reinforce public health strategies, such as practicing physical distancing, wearing masks, washing their hands frequently, and using protective cultural practices and learning these traditions from relatives. The following excerpt from the book exemplifies how public health messaging is intertwined with the promotion of cultural values, such as respect for Elders and others, in a way that demonstrates 


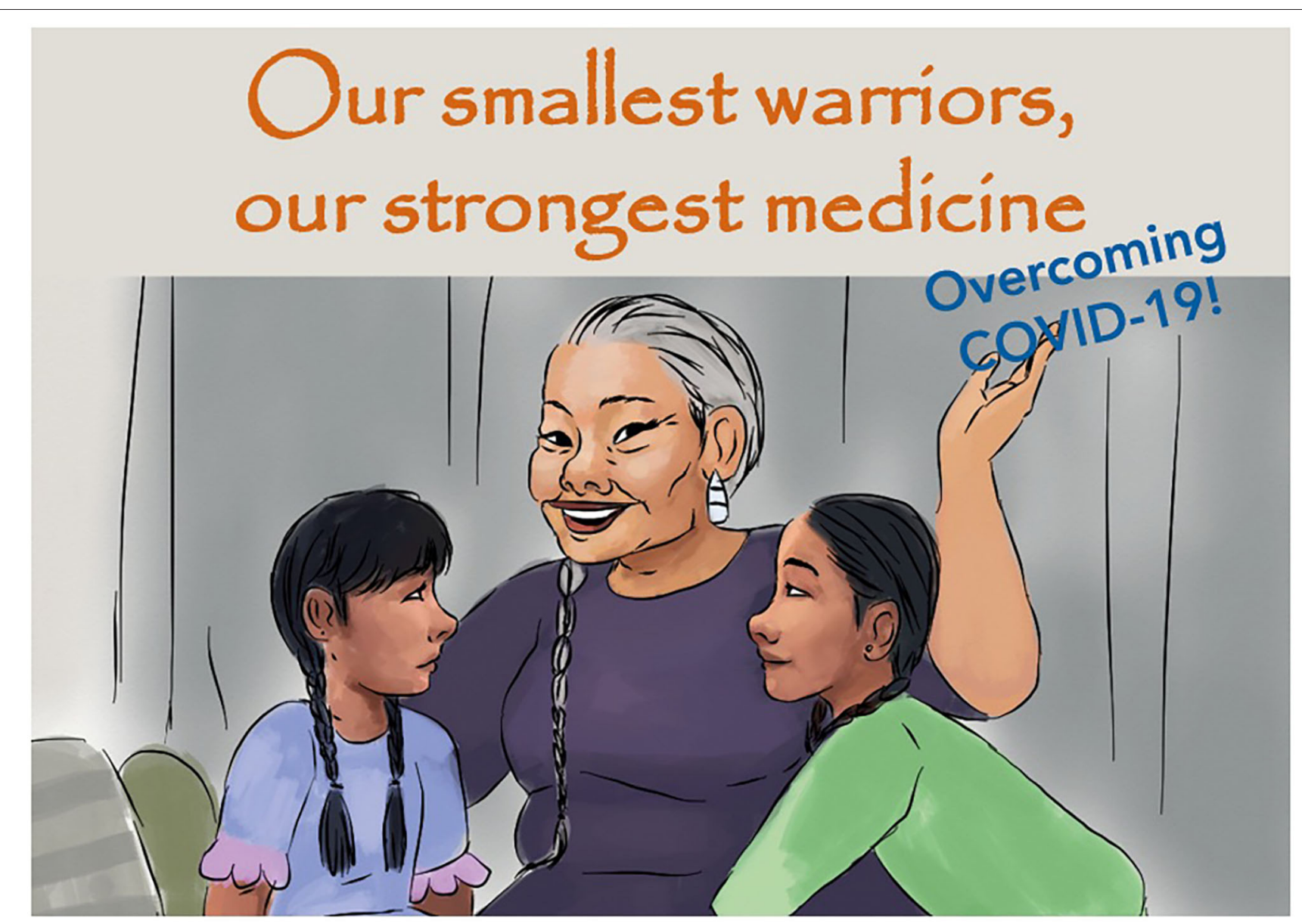

FIGURE 1 | Front cover of "Our Smallest Warriors, Our Strongest Medicine: Overcoming COVID-19."

intergenerational transmission of Indigenous values, traditions, and honors future generations. Jason, the twins' friend from the Northern direction, says:

\section{"We are being extra careful because of my baby sister. We protect her future by telling our friends to stay home and wash their hands as often as they can. This will help keep our Elders and other people safe. We need our community strong so she [the baby sister] can grow up learning our history, language and culture."}

There are also mental health coping strategies integrated throughout the story. For example, the twins talk to their grandmother about feeling scared. Their grandmother comforts them and teaches them to close their eyes and visualize a safe place with their favorite people. In another part of the story, one of their friends who lives near water teaches them a breathing exercise by mimicking making ripples in water to breathe slowly when they feel scared. Recognizing the potential impact of physical distancing on social isolation and loneliness, the story also demonstrates how the twins talk by phone to family and friends and share that they can stay socially connected while adhering to physical distancing guidelines. These pieces of the story are meant to act as important mental health tools to encourage children to talk about their emotions in a safe and comforting environment with others who validate their feelings, as well as learn effective coping and self-regulation strategies.

In addition to the book, nine total parent resource materials and children's activities were collaboratively developed including: (1) counting the ways that the book characters stayed socially connected while staying at home; (2) ideas for how children and families can stay socially connected to others; (3) a family tree activity to recognize and honor relatives; (4) the meaning of earning feathers; (5) ways for parents to feel strong and how to talk with children about their worries during the pandemic and what makes their children feel strong; (6) parent and child self- and co-regulation; (7) identifying and managing stress for parents; (8) tips for reading the book with varying age groups and how to personalize the story; and (9) a vocabulary page defining terms found throughout the book. Further, six coloring pages and six Indigenous language activity pages were developed to promote understanding of intergenerational family connections and traditional languages. These materials were developed based on current recommendations during the COVID-19 pandemic from organizations including Zero to 
Three, American Academy of Pediatrics (AAP), the Centers for Disease Control and Prevention (CDC), Indian Health Service (IHS), and the Substance Abuse and Mental Health Services Administration (SAMHSA).

\section{Dissemination Evaluation}

Indicators of reach demonstrated widescale and diverse dissemination. Regarding print book distribution, 42,364 print books were distributed in all 12 IHS regions in the U.S. Books have reached 105 tribes across 27 states in the U.S., 12 First Nations communities in Canada, 56 intertribal and urban Indigenous health programs (U.S. and Canada), 42 IHS departments, 70 tribal health departments, 44 Family Spirit Affiliates (National Evidence Based Home Visiting Program), 20 Tribal Head Start Programs, 3 libraries, and 5 schools. In addition to this distribution, Indigenous communities, organizations, and health programs have been disseminating materials in their own creative ways. Several tribes, communities, and other organizations have featured "Our Smallest Warriors, Our Strongest Medicine: Overcoming COVID-19" and accompanying resources on their websites, newspapers (print and online), and social media platforms (Table 1). For example, Yakama Nation News featured the book in their summer newsletter along with a tribal language and coloring activity that was developed by CAIH to accompany the book (Figure 2) (Yakama Nation Tribal News, 2020), and featured a story about how the tribal program manager who ordered the books is distributing them within the community (Craig, 2020). The news story featured a photo of a child reading the book with a caption stating that the child shared what she learned about coronavirus with her grandma. Another example of unique ways tribes are interacting with the book is seen in the Pascua Yaqui Tribe Methamphetamine/Suicide Prevention Initiative program sharing a video of a tribal member reading OSWOSM on Facebook and YouTube (Pascua Yaqui Tribe, 2020). The 19-min video features photos from the book as the story is narrated. OSWOSM was also featured in The Navajo Times newspaper (Thacker, 2020) and the Department of Interior's monthly newsletter, Journeys, in their focus on Indigenous Cultures section (Department of the Interior, 2020). Finally, OSWOSM was featured by the World Health Organization in their online video about the global impact of "My Hero is You: How Kids Can Fight COVID-19!.”

Results from the online dissemination strategy indicated 18,975 visits to the book's webpage and more than 119,256 impressions and engagements via social media. The most popular

TABLE 1 | Organizations and communities sharing OSWOSM and resources,

\begin{tabular}{|c|c|c|}
\hline Organization name & Type of mention & URL \\
\hline $\begin{array}{l}\text { All in One Family (weekly Indigenous } \\
\text { storytelling) }\end{array}$ & $\begin{array}{l}\text { Video of book reading, shared link to } \\
\text { resources }\end{array}$ & https://vimeo.com/421518840 \\
\hline $\begin{array}{l}\text { California Indian Basket Weavers } \\
\text { Association }\end{array}$ & Listed in resources & https://ciba.org/covid-19-resources/ \\
\hline Center for Native Youth & $\begin{array}{l}\text { Shared CAlH Facebook post, listed in } \\
\text { resources section }\end{array}$ & $\begin{array}{l}\text { https://www.facebook.com/Center4Native/posts/our-smallest-warriors- } \\
\text { our-strongest-medicine-overcoming-covid-19-this-indigenous/ } \\
\text { 3124105330984997/; } \\
\text { https://www.cnay.org/resource-hub/covid-19-resources/ }\end{array}$ \\
\hline $\begin{array}{l}\text { Federal Emergency Management } \\
\text { Agency }\end{array}$ & Shared resources on weekly blog & https://www.fema.gov/blog/communities-frontline-week-june- 15 \\
\hline Laguna Division of Early Childhood & Listed in resources & http://lagunadec.ss3.sharpschool.com/for_students \\
\hline National Native Child's Trauma Center & Listed in resources & https://www.nnctc.org/covid19-resources \\
\hline Navajo Times & $\begin{array}{l}\text { Interview with Dr. Victoria O'Keefe and } \\
\text { Crystal Kee }\end{array}$ & $\begin{array}{l}\text { https://navajotimes.com/edu/a-book-for-kids-story-focuses-on-smallest- } \\
\text { warriors-to-teach-about-virus/ }\end{array}$ \\
\hline New York City School Library System & Listed in resources & https://nycdoe.libguides.com/COVID-19ebooks/free \\
\hline $\begin{array}{l}\text { North American Association for } \\
\text { Environmental Education }\end{array}$ & Listed in resources & $\begin{array}{l}\text { https://naaee.org/eepro/groups/sustainable-cities-and-communities-k-12/ } \\
\text { discussions/responding-covid-19-through }\end{array}$ \\
\hline Minnesota Autism Resources & Listed in resources & https://mn.gov/autism/covid-19-resources.jsp \\
\hline Pascua Yaqui Methamphetamine and & YouTube video of book reading & https://www.youtube.com/watch?v=G27xR_pjm5k \\
\hline
\end{tabular}

Suicide Prevention Initiative

Red Cliff Community Health Center Listed in resources

State of Michigan Home-Based Early Listed in resources

Childhood Services

U.S. Department of the Interior

Highlighted in their focus on Indigenous peoples during the 2019 coronavirus pandemic

Utah Paiutes

Description of book and links to webpage

World Health Organization

YouTube video

Yəhaw Show

Book mentioned in interview with artist

http://redcliffhealth.org/what-we-do/behavioral-health/native-connections/ https://www.michigan.gov/documents/mde/Home-

based_early_childhood_services_-_Revised_-_07.15.2020_696522_7.pdf

https://www.doi.gov/sites/doi.gov/files/uploads/as-journeys-2020-06-final508-compliant.pdf

https://www.utahpaiutes.org/coronavirus/our-smallest-warriors-ourstrongest-medicine/

https://www.youtube.com/watch?v=l1Q066Kxsrk

https://yehawshow.com/blm-joelle-joyner 


\section{Our smallest warriors, our strongest medicine Overcoming COVID-19!}

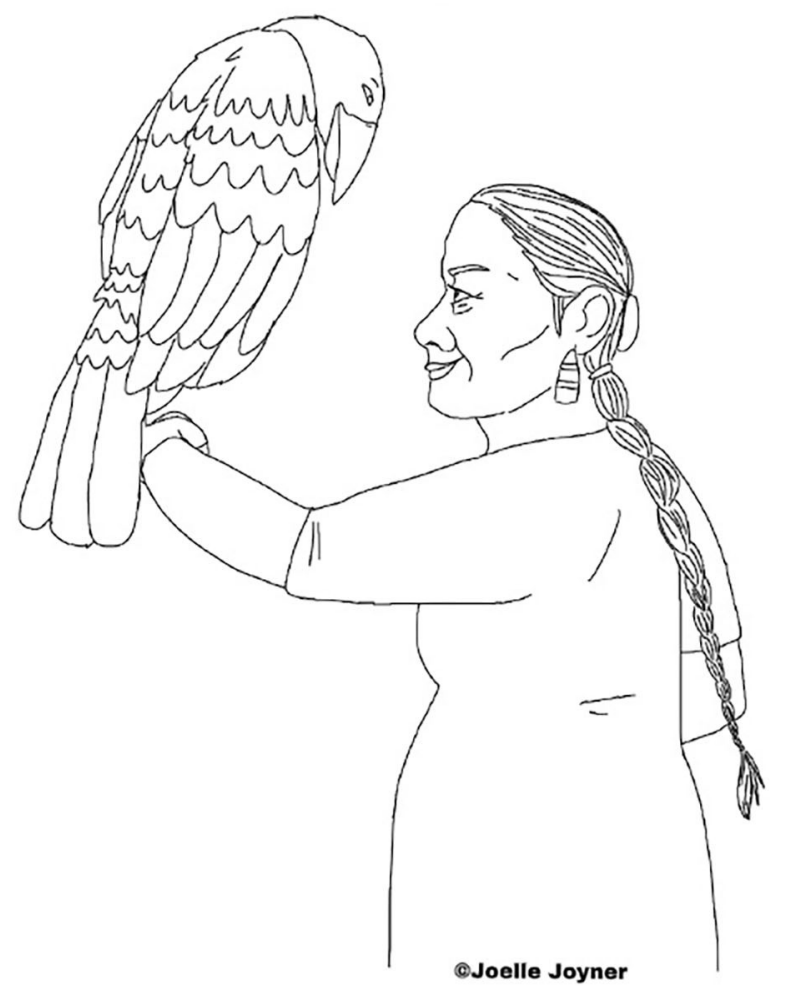

How do you say these words in your language?

Elder:

Eagle:

Respect:

Protect:

Leader:

FIGURE 2 | Coloring and language resource developed by $\mathrm{CAIH}$.

medium for accessing the book's webpage has been Facebook, which has had 91,286 reaches and 4,256 engagements. Other social media platforms included Instagram (668 likes) and Twitter (27,037 impressions). Finally, piloting of the survey measuring the impact of the book with children and families yielded 112 caregiver responses.

\section{DISCUSSION}

"Our Smallest Warriors, Our Strongest Medicine: Overcoming COVID-19" was designed for Indigenous peoples across Turtle Island (North America) to portray a sense of communal efficacy, strength, and hope in the face of the COVID-19 
pandemic. Our cultural adaptation process with a collaborative workgroup aimed to depict Indigenous characters and real community experiences with COVID-19 while providing public health safety messaging and mental health coping strategies. Further, this storybook is framed with an Indigenous strengthsbased lens: (1) the format of this health promotion resource underscores an important Indigenous tradition, storytelling; and (2) the book content and additional resources/activities reflect Indigenous values, teachings, and practices that many families and communities may relate to and which have contributed to intergenerational strengths and wellness. Distribution strategies were derived to reach as many Indigenous families and communities as possible by making the book available free online and in print form for communities who lack broadband access. We continue to see and hear about Indigenous communities and organizations interacting with the book in creative ways and we have sold out of print books, indicating widespread reach and satisfaction.

This project and the resulting children's storybook have some limitations. First, it is challenging to develop Indigenous resources that apply to every tribe, band, village, or community in the U.S. and Canada. The workgroup was faced with the need to balance cultural specificity with concerns of transferability in the adaptation of the storyline. While the adapted storybook is general enough to apply to many Indigenous settings, the context may not be relevant for all readers. In addition, because of the wide geographic reach of the book and its availability online as a downloadable PDF file, it was difficult to implement a rigorous evaluation plan to analyze the book's impacts on mental health coping for children and caregivers. We did pilot an evaluation strategy with a low response rate. However, without a more defined sample and a desire to get the book to as many families as quickly as possible, we did not systematically analyze this data. Yet, this pilot strategy can help inform future iterations of the book and improve our evaluation of the book's impact on family and child functioning and well-being.

These limitations exist alongside numerous strengths. One of these strengths includes an ongoing high demand for print books from tribes, communities, and organizations across the U.S. and Canada, demonstrating that this Indigenous strengthsbased resource is a useful tool during this pandemic. In addition, the book and ancillary materials were developed by a team of mostly Indigenous child development, mental health, health communications, public health professionals and scholars, Elders, and knowledge keepers. It is vital to have narratives that are developed and driven by Indigenous peoples to accurately and respectfully represent and portray community experiences (First Nations Development Institute and Echo Hawk Consulting, 2018)

Future directions of this project include distribution of additional print copies, recording videos of Elders and other community members reading the book to share online, and developing a sequel or potentially a series of books as the public health response to COVID-19 changes over time and across communities. A high priority for the potential series is to portray how K-12 schools (e.g., Bureau of Indian Education, tribally controlled, public, private) are conscientiously preparing and implementing virtual or in-person instruction, public health messaging around safety in differing school or home-based schooling situations, and addressing the potential mental health and psychosocial stress of children, caregivers, and families in the educational context. Indigenous media is highlighting the importance of this topic, as parents and tribal leaders are grappling with schools' re-opening plans (Pember, 2020). In pursuing this topic, we plan to expand our collaboration group to bring in relevant expertise from Indigenous teachers, caregivers, school administrators, and tribal leaders. This future work may include more rigorous evaluation strategies to understand the impact these types of materials have with Indigenous children and families. In addition, future qualitative research may explore the impact OSWOSM has had on Indigenous children and families who have read the book and to better understand Indigenous strengths, knowledges, and practices promoting their well-being during the pandemic and beyond.

The strengths-based approach used in OSWOSM communicates that Indigenous peoples and communities have the historical resilience (House Committee on AppropriationsWritten testimony of Abigail Echo-Hawk, 2020) and cultural knowledge to overcome the COVID-19 pandemic. The book emphasizes that children can help to prevent the spread of COVID-19 in their communities, a unique cultural approach to promoting public health messaging. This approach is not new to Indigenous communities, whose value systems revere children as "considered to be special, sacred gifts" and "carriers of the future" (p. 96; Cajete, 2000). Further, this storybook conveys important teachings about intergenerational, family, community, and environmental connectedness that can promote Indigenous children's wellness (Ullrich, 2019). In remembering and passing on these values and traditions alongside public health messaging in the form of storytelling, "Our Smallest Warriors, Our Strongest Medicine: Overcoming COVID-19" aligns with the cultural strengths of Indigenous communities and exemplifies on many levels shared traditional beliefs that children are "strong medicine."

\section{DATA AVAILABILITY STATEMENT}

The original contributions presented in the study are included in the article/supplementary material, further inquiries can be directed to the corresponding author.

\section{AUTHOR CONTRIBUTIONS}

VO'K, TM, AI, CK, KM, AB, and EH drafted, reviewed, and approved this manuscript. In addition, a collaboration team (see Acknowledgments for list) reviewed and/or approved of this manuscript.

\section{FUNDING}

This project was funded by the Johns Hopkins Alliance for a Healthier World (www.ahealthierworld.jhu.edu), a universitywide initiative focused on solving health equity and social 
justice issues around the world, as well as the Johns Hopkins Office of the President and Office of the Provost. This project was also funded by UNICEF USA (www.unicefusa.org), an organization dedicated to advancing the global mission of UNICEF by rallying the American public to support the world's most vulnerable children.

\section{ACKNOWLEDGMENTS}

This book was an adaptation from a book created by the InterAgency Standing Committee (IASC) Reference Group on Mental Health and Psychosocial Support and as such we would like to thank them for their support in this process.

We humbly acknowledge and express our deep gratitude to our collaboration team (listed below) who helped us re-write and illustrate "Our Smallest Warriors, Our Strongest Medicine: Overcoming COVID-19" and reviewed and/or approved of this manuscript.

Michelle Archuleta, MA, MS (Lone Pine Paiute-Shoshone), Public Health Advisor, Division of Clinical and Community Services, Indian Health Service.

Alberta Becenti, MPH (Diné), Public Health Advisor, Division of Clinical and Community Services, Indian Health Service.

\section{REFERENCES}

Arriagada, P., Hahmann, T., and O’Donnell, V. (2020). "Indigenous people and mental health during the COVID-19 pandemic," in STATCAN COVID-19: Data to Insights for a Better Canada (Ottawa: Statistics Canada).

Barlow, A., Mullany, B., Neault, N., Compton, S., Carter, A., Hastings, R., et al. (2013). Effect of a paraprofessional home-visiting intervention on American Indian teen mothers' and infants' behavioral risks: a randomized controlled trial. Am. J. Psychiatry 170, 83-93. doi: 10.1176/appi.ajp.2012. 12010121

Barlow, A., Mullany, B., Neault, N., Goklish, N., Billy, T., Hastings, R., et al. (2015). Paraprofessional-delivered home-visiting intervention for American Indian teen mothers and children: 3-year outcomes from a randomized controlled trial. Am. J. Psychiatry 172, 154-162. doi: 10.1176/appi.ajp.2014.14030332

Barlow, A., Varipatis-Baker, E., Speakman, K., Ginsburg, G., Friberg, I., Goklish, N., et al. (2006). Home-visiting intervention to improve childcare among American Indian adolescent mothers: a randomized trial. Arch. Pediat. Adolesc. Med. 160, 1101-1107. doi: 10.1001/archpedi.160.11.1101

Brave Heart, M. Y., and Debruyn, L. M. (1998). The American Indian holocaust: healing historical unresolved grief. Am. Indian Alaska Native Ment. Health Res. 8, 56-78. doi: 10.5820/aian.0802.1998.60

Cajete, G. (2000). Native Science: Natural Laws of Interdependence. Santa Fe: Clear Light Pub.

Centers for Disease Control and Prevention (n.d.). Coronavirus Disease 2019 (COVID-19) [Online]. Centers for Disease Control and Prevention. Available online at: https://www.cdc.gov/coronavirus/2019-ncov/covid-data/covidview/ index.html (accessed August 16, 2020).

Craig, C. (2020, July 30). Tribal children affected by COVID-19: our smallest warriors our strongest medicine. Yakama Nation Review.

Department of the Interior (2020). Focus on Indigenous Cultures: "Our Smallest Warriors, Our Strongest Medicine”. Washington DC: Journeys. Department of the Interior.

First Nations Development Institute and Echo Hawk Consulting (2018). Research Findings: Compilation of all Research. Reclaiming Native Truth.

Harris, P. A., Taylor, R., Thielke, R., Payne, J., Gonzalez, N., and Conde, J. G. (2009). Research electronic data capture (REDCap)-A metadata-driven methodology
Joshuaa Allison-Burbank, PhD, CCC-SLP (Diné and Acoma Pueblo), Northern Navajo Medical Center, Shiprock, New Mexico.

Miranda Carman, LCSW (Muscogee Creek Nation), Public Health Consultant, Division of Behavioral Health, Indian Health Service.

Suzanne England, MD, Women's Health/MCH Consultant, Aberdeen Area Office, Indian Health Service.

Crystal Kee, BS (Diné Nation), Program Consultant, Center for American Indian Health, Johns Hopkins Bloomberg School of Public Health.

Lisa Martin, MPH (Ojibwe), Inter-Tribal Council of Michigan.

Joelle Joyner (Kauwets'a:ka/Tsalagi/Pikuni), Freelance Artist, Illustrator, Undergraduate Student at Wayne State University.

Marcella Ronyak, PhD, LCSW, CDP (Confederated Tribes of the Colville Reservation), Director, Division of Clinical and Community Services, Indian Health Service.

We also want to express our heartfelt gratitude and hope to all strong, Indigenous communities coping with the COVID-19 pandemic. This storybook is dedicated in loving memory to our relatives whose lives have been lost to COVID-19 and all the frontline workers whose relentless efforts have saved so many.

and workflow process for providing translational research informatics support. J. Biomed. Inform. 42, 377-381. doi: 10.1016/j.jbi.2008.08.010

Hatcher, S., Agnew-Brune, C., Anderson, M., Zambrano, L., Rose, C., Jim, M., et al. (2020). COVID-19 among American Indian and Alaska Native Persons - 23 States, January 31-July 3, 2020. MMWR Morb. Mortal Wkly Rep. 69, 1166-1169. doi: 10.15585/mmwr.mm6933e4

House Committee on Appropriations-Written testimony of Abigail Echo-Hawk (2020). Subcommittee on Interior, Enviornment and Related Agencies. Available online at: https://www.congress.gov/116/meeting/house/110378/witnesses/ HHRG-116-AP06-Wstate-Echo-HawkA-20200212.pdf (accessed Febuary 12, 2020).

Indian Health Service (2020a). Financial Year 2021 Performance Budget Submission to Congress. Available online at: https://www.ihs.gov/sites/ budgetformulation/themes/responsive2017/display_objects/documents/FY 2021_Final_CJ-IHS.pdf (accessed December 15, 2020).

Indian Health Service (2020b). IHS Covid-19 Response Webinar Series: Emotional Wellbeing for American Indians during COVID-19 Crisis: Implications of Historical Trauma and the Historical Trauma Response Features. Rockville, MD: Indian Health Service.

Inter-Agency Standing Committee (2020). My Hero is You, Storybook for Children on COVID-19 [Online]. Inter-Agency Standing Committee. Available online at: https://interagencystandingcommittee.org/iasc-reference-group-mentalhealth-and-psychosocial-support-emergency-settings/my-hero-you (accessed August 13, 2020).

King, M., Smith, A., and Gracey, M. (2009). Indigenous health part 2: the underlying causes of the health gap. Lancet 374, 76-85. doi: 10.1016/S0140-6736(09)60827-8

Kovach, M. (2010). Indigenous Methodologies: Characteristics, Conversations, and Contexts. Toronto, ON: University of Toronto Press.

Nabokov, P. (1999). Native American Testimony: A Chronicle of IndianWhite Relations From Prophecy to the Present, 1492-2000. London: Penguin Group USA.

National Congress of American Indians (n.d.). Telecommunications and Technology [Online]. Washington, DC: National Congress of American Indians. Available online at: http://www.ncai.org/policy-issues/economicdevelopment-commerce/telecomm-and-tech (accessed August 16, 2020). 
National Indian Health Board (2020). "Considerations for tribal funeral and burial ceremonies during the time of COVID-19," in National Tribal COVID-19 Response (Washington, D.C.: National Indian Health Board).

National Tribal Health Budget Formulation Workgroup (2020). Reclaiming Tribal Health: A National Budget Plan to Rise Above Failed Policies and Fulfill Trust Obligations to Tribal Nations. Available online at: https://www.nihb.org/docs/ 05042020/FINAL_FY22\%20IHS\%20Budget\%20Book.pdf (accessed December $15,2020)$.

Native Governance Center (n.d.). Tribal Sovereignty and COVID-19. Available online at: https://nativegov.org/tribal-sovereignty-and-covid-19/ (accessed December 15, 2020).

Pascua Yaqui Tribe (2020). Narrated by Bridget Valenzuela, MEd, BHT, Pascua Yaqui Tribe, Meth/Suicide Prevention Initiative (MSPI/SASP). Available online at: https://www.youtube.com/watch?v=G27xR_pjm5k

Pember, M. A. (2020, August 13). Bureau of Indian Education: Open schools or else. Indian Country Today.

Qualtrics (2020). Development Company: Qualtrics Version: 2020. Provo, UT. Available online at: https://www.qualtrics.com/ (accessed December 15, 2020).

Rodriguez-Lonebear, D., Barceló, N. E., Akee, R., and Carroll, S. R. (2020). American Indian reservations and COVID-19: correlates of early infection rates in the pandemic. J. Pub. Health Manage. Pract. 26, 371-377. doi: 10.1097/PHH.0000000000001206

Smith, L. T. (2013). Decolonizing Methodologies: Research and Indigenous Peoples. London: Zed Books Ltd.

Thacker, S. (2020, July 9). A book for kids: Story focuses on 'smallest warriors' to teach about virus. Navajo Times.

U.S. Commission on Civil Rights (2018). BROKEN PROMISES: Continuing Federal Funding Shortfall for Native Americans. Washington, DC: U.S. Commission on Civil Rights.

U.S. Commission on Civil Rights-Written testimony of President Fawn Sharp, National Congress of American Indians (2020). Hearing on COVID-19 in Indian Country: The Impact of Federal Broken Promises on Native Americans.
Available online at: https://www.ncai.org/attachments/Testimonial DZsioKxiANtlqzyGvRcGDaWpLsbZjlzhnmJpREpHubPVEyMOlYO_NCAIWritten-Testimony-USCCR\%207_17_20-Hearing.pdf (accessed July 17, 2020).

Ullrich, J. S. (2019). For the love of our children: an Indigenous connectedness framework. AlterNative 15, 121-130. doi: 10.1177/1177180119828114

Urban Indian Health Board (2020). Physically Distant but Socially Close: Indigenous Resilience and COVID-19. Seattle, WA: Urban Indian Health Board.

Vizenor, G. (2008). Survivance: Narratives of Native presence. Lincoln, NE: U of Nebraska Press.

Walkup, J. T., Barlow, A., Mullany, B. C., Pan, W., Goklish, N., Hasting, R., et al. (2009). Randomized controlled trial of a paraprofessionaldelivered in-home intervention for young reservation-based American Indian mothers. J. Am. Acad. Child Adolesc. Psychiatry 48, 591-601. doi: 10.1097/CHI.0b013e3181a0ab86

Walters, K. L., Johnson-Jennings, M., Stroud, S., Rasmus, S., Charles, B., John, S., et al. (2020). Growing from our roots: strategies for developing culturally grounded health promotion interventions in American Indian, Alaska Native, and Native Hawaiian communities. Prevent. Sci. 21, 54-64. doi: 10.1007/s11121-018-0952-z

Yakama Nation Tribal News (2020). Activities for Miyanashma. Yakama Nation Tribal News (Toppenish, WA: Yakama Nation).

Conflict of Interest: The authors declare that the research was conducted in the absence of any commercial or financial relationships that could be construed as a potential conflict of interest.

Copyright (C) 2021 O'Keefe, Maudrie, Ingalls, Kee, Masten, Barlow and Haroz. This is an open-access article distributed under the terms of the Creative Commons Attribution License (CC BY). The use, distribution or reproduction in other forums is permitted, provided the original author(s) and the copyright owner(s) are credited and that the original publication in this journal is cited, in accordance with accepted academic practice. No use, distribution or reproduction is permitted which does not comply with these terms. 